Revista Perspectivas Online: Biológicas \& Saúde Novembro de 2017, Vol.7, no 25, p. 1- 24

ISSN: 2236-8868 (Online)

DOI: $10.25242 / 886872520171136$

\title{
EFETIVIDADE DAS MEDIDAS DE PREVENÇÃO E CONTROLE DE PNEUMONIA ASSOCIADA À VENTILAÇÃO MECÂNICA NA UTI
}

\author{
Thatiany Batista Paes Nascimento ${ }^{1}$, Criscila Henriques Ramos ${ }^{1}$, Thiago dos Santos Silva ${ }^{1}$ \& \\ Vanessa Pio dos Santos Torres ${ }^{2 *}$
}

NASCIMENTO, T.B.P.; RAMOS, C.H.; SILVA, T.S. \& TORRES, V.P.S. Efetividade das medidas de prevenção e controle de pneumonia associada à ventilação mecânica na UTI. Perspectivas Online: Biológicas e Saúde, v.7, n.25, p.1-24, 2017.

\section{RESUMO}

A Pneumonia Associada à Ventilação Mecânica (PAVM) é considerada a segunda infecção mais frequente nas UTIs Americanas, e na Europa. Destacando o Brasil, estudos revelam que a PAVM é uma das maiores infecções hospitalares resultando em altos índices de internações prolongadas. A Sociedade Brasileira de Pneumologia define a PAVM como aquela que ocorre após $48 \mathrm{~h}$ a instalação de ventilação mecânica. O estudo objetivou-se em destacar a importância da implementação das medidas de prevenção e controle da PAVM na UTI pelos profissionais de enfermagem. A metodologia adotada foi a pesquisa exploratória, descritiva e observacional com abordagem quantitativa, desenvolvida na UTI de um hospital de grande porte no município de Campos dos Goytacazes RJ, no período de setembro a dezembro/2015, e compuseram a amostra 51 pacientes que estavam em uso de prótese ventilatória. Na UTI do hospital referido foi obtido um percentual significativo de pacientes diagnosticados com PAVM referente a $27,4 \%$. Pode-se ressaltar a conformidade de geral de $33,3 \%$ e não conformidade geral de $66,6 \%$. Este cenário demonstrou que as medidas foram realizadas de forma insatisfatória pelos profissionais de enfermagem, evidenciando baixa adesão as medidas essenciais para minimizar a incidência de PAVM.

Palavras-chave: Pneumonia; Infecções Hospitalares; Unidade de Terapia Intensiva; Cuidados de Enfermagem. 


\begin{abstract}
Mechanical Ventilation Associated Pneumonia (PAVM) is considered the second most frequent infection in American ICUs, and in Europe. Highlighting Brazil, studies show that VAP is one of the largest hospital infections resulting in high rates of prolonged hospitalizations. The Brazilian Society of Pulmonology defines PAVM as the one that occurs after 48 hours the installation of mechanical ventilation. The study aimed to highlight the importance of the implementation of measures of prevention and control of VAP in the ICU by the nursing professionals. The methodology used was the exploratory, descriptive and observational study with a

quantitative approach, developed in the ICU of a large hospital in the municipality of Campos dos Goytacazes RJ, from September to December / 2015, and the sample consisted of 51 patients who were in Use of ventilatory prosthesis. In the ICU of the mentioned hospital a significant percentage of patients diagnosed with VAP were obtained, corresponding to $27.4 \%$. Overall compliance of $33.3 \%$ and overall non-compliance of $66.6 \%$ can be highlighted. This scenario demonstrated that the measurements were performed unsatisfactorily by nursing professionals, showing low adherence to the essential measures to minimize the incidence of VAP.
\end{abstract}

Keywords: Pneumonia; Hospital Infections; Intensive Care Unitis; Nursing Care.

\footnotetext{
${ }^{1}$ Acadêmicos em Enfermagem do ISECENSA - Rua Salvador Correa, 139, Centro, Campos dos Goytacazes, RJ, CEP: 28035-310, Brasil;

${ }^{2}$ Enfermeira Intensivista/ UERJ/RJ e professora do ISECENSA - Rua Salvador Correa, 139, Centro, Campos dos Goytacazes, RJ, CEP: 28035-310, Brasil;

(*) e-mail: torres.vanessapio@yahoo.com.br

Data de chegada: 13/03/2017 Data para publicação: 30/11/2017
}

Persp. online: biol. \& saúde, Campos dos Goytacazes, 25 (7), 1-24, 2017

seer.perspectivasonline.com.br 


\section{INTRODUÇÃO}

A Pneumonia Associada à Ventilação Mecânica (PAVM) é aquela que desenvolve-se após 48h de ventilação mecânica, excluindo-se os casos de pneumonias como causa da insuficiência respiratória. É considerada a segunda infecção mais frequente em UTIs americanas e a mais frequente na Europa. Entretanto no Brasil estudos individuais demonstram que a PAVM é considerada como uma das maiores causas de infecções hospitalares que conduzem altos índices de internações prolongadas, aumento dos custos hospitalares e consequentemente agravos no quadro clínico de pacientes (Sociedade Brasileira de Pneumologia, 2013).

Tendo em vista, que a PAVM é considerada uma das maiores infecções hospitalares, um estudo conduzido em 99 hospitais brasileiros, demonstrou que do total de infecções no ambiente hospitalar, 28,9\% foi de pneumonia e, destas, $50 \%$ ocorreram em pacientes ventilados mecanicamente na unidade de terapia intensiva (BRASIL, 2014).

A UTI destina-se ao cuidado intensivo, ininterrupto a pacientes graves ou de risco, tais pacientes podem apresentar comprometimento em seus sistemas fisiológicos o que resulta muitas vezes na perda da sua capacidade de autorregularão, sendo potencialmente recuperáveis com auxílio de equipe multiprofissional, alta tecnologia e recursos humanos especializados (JERONIMO, 2010).

Bork, Gaspar e Reche (2015), afirmam que pacientes internados na UTI, estão expostos a uma ampla variedade de microrganismos patogênicos, tal setor representa menos de $2 \%$ dos leitos hospitalares disponíveis, porém favorece com de $25 \%$ das infecções hospitalares, com significativo impacto nos índices de morbidade e mortalidade.

A manutenção da vida dos pacientes críticos em sua maioria ocorre através da substituição de funções orgânicas por métodos artificiais, necessitando de monitorização e suporte contínuo para manter estáveis as funções vitais aumentando a sobrevida desses pacientes. Dentre esses métodos pode-se citar a ventilação mecânica ou a traqueostomia que, por sua vez, rompem as barreiras imunológicas, afetam os mecanismos de defesas do trato respiratório, tais intervenções também podem ser danosas expondo-os a riscos de adquirir infecções comprometendo de forma significativa a sua recuperação (GOMES, 2016; PERUGINI et al., 2015; MELO et al., 2015).

A infeção hospitalar decorrente das complicações é descrita como qualquer infecção adquirida após a internação hospitalar ou pode manifestar-se logo após a alta, quando relacionada com o procedimento ou internação, em contrapartida difere-se de outras patologias por ser causada por agentes múltiplos e por sua cadeia de transmissão ser muito variável. Assim, destaca-se a pneumonia que quando associada à ventilação mecânica sua incidência é de $86 \%$ com a prevalência de 20,5 a 34,4 casos por 1.000 dias de VM, tendo uma variação entre $10 \%$ e $50 \%$ para desenvolver a doença com risco aproximado de $1 \%$ a $3 \%$ por dia de VM, podendo elevar os custos hospitalares e aumento do tempo de internações repercutindo de forma expressiva no quadro do paciente tendo como principal consequência mortalidade (ALMEIDA et al., 2015; CALIL et al., 2014).

Frente a esta problemática foi lançada uma campanha "Protecting 5 Million Lives", coordenada pelo Institute Healthcare Improvement (IHI), que consistiu em promover a prevenção das Infecções Relacionadas à Assistência em Saúde (IRAS) em procedimentos invasivos. Recomendam-se pacotes de medidas preventivas, nomeados "bundles", que individualmente resultam em melhoria da assistência, e, quando implantadas em conjunto, resultam em melhorias ainda mais expressivas (CAMBRIDGE, 2008).

A equipe de enfermagem dispõe da maioria dos cuidados à vida dos pacientes críticos em uma UTI de forma ininterrupta, o que implica ao enfermeiro a vivenciar um desafio na edificação do conhecimento sobre o qual se fundamenta sua prática, ainda como parte desse desafio elenca-se o desenvolvimento do

Persp. online: biol. \& saúde, Campos dos Goytacazes, 25 (7), 1-24, 2017

seer.perspectivasonline.com.br 
processo de trabalho da enfermagem com objetivo de promover, manter ou restaurar o nível de saúde desses pacientes (CHAGAS, PEREIRA; CASTRO 2015).

Ao discorrer sobre cuidados a pacientes críticos em UTI, é necessário enfatizar a humanização, isto é, tornar humano e complacente, sendo compreendida como um modo que busca resgatar o respeito a vida humana nos aspectos sociais, fisiológicos e biológicos. Dessa forma é necessário que o profissional frente ao paciente adote uma prática considerando o conjunto desses aspectos como parte da sua assistência humanizada, assumindo uma posição ética de respeito ao próximo (COLAÇO et al., 2015).

Segundo o Center for Disease Control and Prevention (CDC) 2016, algumas medidas de prevenção de PAVM são fundamentadas em quatro critérios: conhecimento dos profissionais de saúde acerca do controle e de prevenção; a vigilância e notificação de casos diagnosticados; prevenção da transmissão por microrganismos e minimizar o risco para infecção.

Marras \& Lapena (2015) afirmam que a equipe multiprofissional exerce papel fundamental no que diz respeito à prevenção das infecções no ambiente hospitalar, o que implica a equipe de saúde adoção de medidas preventivas padronizadas, treinamento de equipes, educação continuada no processo assistencial com vistas a evitar falhas neste processo, uma vez que a PAVM é de origem infecciosa com diagnostico multicausal.

Assim, justifica-se a importância e relevância da presente pesquisa, que propõe abordar os cuidados voltados para o indivíduo submetidos à ventilação mecânica, pois a equipe enfermagem compõe a força motriz dos cuidados assistenciais, e necessita estar capacitada para evitar eventos adversos.

Diante ao exposto, a pesquisa teve como objetivo destacar a importância da implementação das medidas de prevenção e controle da pneumonia associada à ventilação mecânica pela equipe de enfermagem na unidade de terapia intensiva.

\section{METODOLOGIA}

A pesquisa realizou-se na UTI Adulta de uma instituição pública referência no atendimento de emergência em Campos dos Goytacazes, RJ. O hospital, que existe há 59 anos, é reconhecido pelo Ministério da Saúde com classificação de Nível III (máximo) em atendimento de emergência. Optou-se pela determinada instituição devido o elevado quantitativo de leitos (24 leitos), consequente demanda de profissionais de enfermagem na UTI e também por ser referência no atendimento de emergência na rede Sistema Único de Saúde (SUS).

Os sujeitos da pesquisa foram 51 pacientes de ambos os sexos internados no setor de UTI dessa unidade, em uso de prótese ventilatória, rebaixamento do nível de consciência e/ou uso de sondas digestivas excluindo-se da pesquisa pacientes diagnosticados com pneumonia na admissão hospitalar ou aqueles que desenvolveram nas primeiras 24 de internação na UTI.

A coleta de dados foi realizada através de dois instrumentos, aplicados no período de $07 \mathrm{~h}$ as $12 \mathrm{~h}$, entre setembro a novembro de 2015 são eles:

Instrumento I: Impresso de caracterização que foi alimentado por meio da análise de prontuário do paciente a fim de conhecer os fatores específicos da clínica, tais como, tempo de internação e diagnóstico de pneumonia. Sendo seguido por preenchimento de um checklist observacional referenciado nas evidências científicas de bundles, guidelines e manuais (Agência de Vigilância Sanitária Brasileira), com base nas orientações de ações e boas práticas para a prevenção e controle da PAVM. Este foi alimentado por meio de observação direta não-participante dos procedimentos assistenciais dispensados aos pacientes que se enquadrarem nos critérios de inclusão desta pesquisa.

Persp. online: biol. \& saúde, Campos dos Goytacazes, 25 (7), 1-24, 2017

seer.perspectivasonline.com.br 
Instrumento II: Foi utilizado o Indicador de Avaliação da Adesão às Medidas de Prevenção e Controle de Pneumonia em Pacientes de Alto Risco (IRPR), o qual foi desenvolvido e validado por especialistas sendo disponibilizado no Manual de Indicadores de Avaliação de Práticas de Controle de Infecção Hospitalar, sendo de domínio público esse instrumento é composto por uma planilha e fundamentado na observação da aplicabilidade de medidas de prevenção e controle de pneumonia hospitalar, tais como: decúbito elevado, utilização de soluções estéreis nos equipamentos de terapia respiratória, fisioterapia respiratória, e adesão à rotina de troca dos inaladores estabelecida na instituição (Secretaria da Saúde do estado de São Paulo, 2006).

O instrumento I possibilitou conhecer a incidência de pneumonia e relacioná-la com a efetividade da implementação de medidas preventivas. Os dados coletados foram digitados no programa Microsoft Office Excel versão: 14.0. Ano 2010 para Windows com análise estatística descritiva.

$\mathrm{O}$ instrumento II possibilitou registrar as avaliações e um constructo operacional que orienta e explica a aplicação da avaliação da prática que o corresponde. As operações são dispostas de forma concreta indicando o que se avalia como proceder a coleta de informações e como devem ser mensuradas, visando garantir uniformidade na avaliação e legitimidade na representação empírica dos dados, apresentando melhor prática disponível, fundamentada cientificamente, possibilitando calcular os índices de conformidades após avaliação.

Para calcular os índices de conformidade das práticas contidas no indicador, foi utilizada a fórmula recomendada pelo Construto Operacional dos Indicadores de Avaliação de Práticas de Controle e Prevenção de Infecção Hospitalar. O Controle e prevenção de infecção respiratória descrita abaixo, analisando-se a conformidade geral do IRPR e a conformidade de cada componente do indicador.

$\mathrm{N}^{\mathrm{o}}$ total de pacientes sob assistência ventilatória, com rebaixamento de consciência e ou nutrição por sondas digestivas em que todos os componentes de controle para pneumonia hospitalar estão corretamente aplicados. $\mathrm{x} 100$

$\mathrm{N}^{\circ}$ total de pacientes avaliados, sob as condições descritas no numerador.

A planilha é composta por quatro categorias de evidências relacionadas aos procedimentos de assistência respiratória sendo elas: Soluções estéreis (A); Inalador e/ou umidificador respeitando a rotina de troca estabelecida (C); Atendimento diário de fisioterapia respiratória (C); Decúbito elevado a 30-45 (C), que foram analisadas pelos seguintes critérios de avaliação: A (atende); NA (não atende); AP (atende parcialmente) IN (inaplicável, quando o serviço não é realizado); registrar Sem Aplicação (SA) nos casos em que o paciente tenha contraindicação de algum procedimento descrito pelo IRPR.

Dentre os critérios de avaliação o uso de soluções estéreis para nebulizadores e umidificadores foi utilizado à observação direta, considerando Atende (A) quando não forem encontrados frascos de água destilada abertos ou seringas com soros fisiológicos preparados; os circuitos de terapia inalatória (inalador e/ou umidificador) em uso e respeitando a rotina de troca estabelecida, foi verificada através da avaliação direta sob a existência de rotina descrita para cuidado com estes materiais e checar se a mesma está sendo seguida com a avaliação indireta de acordo com as informações contidas no prontuário quanto a prescrição de enfermagem ou fisioterapia com registro das trocas; o atendimento diário de fisioterapia respiratória foi analisado através da observação direta e indireta pelo prontuário do paciente, procurar as informações na evolução e anotações da equipe de fisioterapia e cabeceira elevada a $30-40^{\circ}$ através da observação direta.

Persp. online: biol. \& saúde, Campos dos Goytacazes, 25 (7), 1-24, 2017

seer.perspectivasonline.com.br 
O projeto encontra-se aprovado pelo CEP - ISECENSA no dia 15/08/2015 de acordo com a resolução n 466/12 sob número de CAAE: 47287115.8.0000.5524 . Versão: 1.

\section{RESULTADOS E DISCUSSÃO}

Para caracterização da amostra foi realizada uma análise documental através da leitura dos materiais disponíveis na instituição, tais como: prontuários contendo todas as informações pertinentes a clínica dos pacientes, tempo de permanência na UTI, com evoluções e prescrições de toda a equipe multidisciplinar desta unidade, ainda foi possível observar os protocolos como os checklists (bundles), que são preenchidos exclusivamente pelos enfermeiros que atuam no setor.

Através destes, foi observado que as fases desses impressos são realizadas, porém pode-se mencionar a fragmentação do conteúdo através de impressos incompletos que são preenchidos pelos profissionais durante a evolução dos preenchimentos.

Conforme a Resolução COFEN - 358/2009 que revoga a Resolução COFEN no 272/2002, designa em seu artigo $1^{\circ}$ que é privativo ao enfermeiro a "implantação, planejamento, organização, execução e avaliação do processo de enfermagem, que compreende as seguintes etapas: histórico de enfermagem, exame físico, diagnóstico de enfermagem, prescrição de enfermagem e evolução".

Diante o exposto, a inadequação do registro de enfermagem, segundo a resolução descrita acima, transforma a Sistematização da Assistência de Enfermagem (SAE) incompleta, demonstrando controvérsia entre o que é determinado e o que é aplicado.

A análise dos resultados obtidos proporcionou a construção do perfil clínico epidemiológico dos pacientes internados em UTI submetidos a suporte ventilatório invasivo.

A PAVM além de compor um grupo significativo de infecções na UTI, é considerada uma Infecção Relacionada à Assistência à Saúde (IRAS), representando números expressivos nas taxas de morbimortalidade, repercutindo, progressivamente, em danos e agravos à saúde dos indivíduos expostos a tal enfermidade, refletindo assim, significativamente no tempo de internação hospitalar e custos assistenciais para as instituições de saúde e o usuário em questão (SILVA, NASCIMENTO; SALLES 2012).

Durante o período de realização do estudo, foi possível observar 51 pacientes. No que tange ao suporte ventilatório destaca-se que 64,7\% pacientes estavam em uso de Tubo Orotraqueal (TOT), e 35,2\% em uso da Traqueostomia (TQT), ambos acoplados a ventilação mecânica, configurando critério de inclusão da amostra. Ainda relatando critérios de inclusão para o estudo, destaca-se que todos os componentes, ou seja, $100 \%$ pacientes encontravam-se com rebaixamento de nível de consciência (sedação), e em uso de sonda enteral, validando dados que alimentaram o IRPR, descritos na tabela 1.

Tabela 1: Dados referentes à amostra do estudo (n=51) - Campos dos Goytacazes, RJ - 2016.

\begin{tabular}{c|c|c}
\hline Item & N & $\%$ \\
\hline Acoplado em Suporte ventilatório TOT & 33 & 64,7 \\
Acoplado em Suporte ventilatório TQT & 18 & 35,2 \\
Rebaixamento de nivel de consciência & 51 & 100 \\
Uso de sonda enteral & 51 & 100 \\
\hline
\end{tabular}

Persp. online: biol. \& saúde, Campos dos Goytacazes, 25 (7), 1-24, 2017

seer.perspectivasonline.com.br 
A necessidade de suporte ventilatório é decorrente da incapacidade, temporária ou não, do sistema respiratório em desempenhar suas funções, de forma a atender as necessidades do paciente, onde a VM apresenta-se como um importante instrumento utilizado para a recuperação dos pacientes críticos internados em UTI, entretanto expõem estes a riscos de adquirir a pneumonia associada ao ventilador mecânico, sobretudo pela diminuição das defesas naturais das vias aéreas superiores (MELO et al., 2015).

Atualmente o uso traqueostomia está entre os procedimentos cirúrgicos mais comumente realizados em pacientes gravemente enfermos, tendo indicação para os que necessitam de suporte ventilatório invasivo prolongado, no manuseio dos portadores de desmame difícil da prótese ventilatória ou para facilitar a higiene das vias aéreas, oferecendo maior segurança e conforto para o paciente, permitindo a retirada do tubo orotraqueal e a diminuição da sedação durante a VM (LISBOA et al., 2012).

Pesquisas recentes revelam benefícios significativos da traqueostomia precoce em relação a um bom prognostico dos resultados clínicos, incluindo redução na duração da ventilação mecânica, no número de internações na UTI e, consequentemente, na incidência de pneumonia adquirida, que é diretamente associada à ventilação mecânica; os principais fatores responsáveis por tais resultados apresentados são a diminuição de sedação e a mobilidade precoce do paciente, entretanto, restam muitas dúvidas a respeito de qual seria a definição de traqueostomia precoce consiste naquela realizada com 7 ou 10 dias de ventilação mecânica e acerca de para quais pacientes essa técnica seria mais benéfica (FERREIRA; CAVENAGHI, 2011).

Reforçando as vantagens da traqueostomia em relação ao tubo orotraqueal, Cardoso et al. (2014) afirmam que a traqueostomia (TQT) é capaz de reduzir o risco de auto-extubação, promove mais conforto para o paciente, possibilita este a receber nutrição por via oral, melhor higiene oral e maior facilidade para enfermagem no manuseio do paciente.

Os principais fatores predisponentes à lesão da mucosa correspondem tempo de intubação, antecedentes de intubação difícil ou traumática, intubações repetidas, material do tubo, fixação inadequada da cânula e movimentos repetidos do paciente, intubação muito alta (com a ponta do tubo no terço superior da traqueia), infecção das vias aéreas superiores e manuseio inadequado da equipe de enfermagem (CARDOSO et al., 2014).

Observou-se de forma geral que $100 \%$ dos pacientes estavam com rebaixamento de nível de consciência registrado em prontuário, durante a internação na UTI, e verificou-se que estes ainda receberam algum tipo de sedação, visto que encontravam-se em uso de suporte ventilatório invasivo, portanto, o uso dessas medicações torna-se necessário a fim de manter a sincronia entre o paciente e o ventilador mecânico.

Em contrapartida, tendo em vista que a sedação é uma situação dinâmica que se apresenta em gradação, é fundamental que seja realizado o acompanhamento contínuo do paciente, o qual é baseado em escalas. Sendo assim, O rebaixamento do nível de consciência nos pacientes compõe um dos fatores de risco para o desenvolvimento de PAVM, visto que, o paciente perde alguns de seus reflexos fisiológicos como de deglutição aumentando o risco de broncoaspiração por estarem com sondas digestivas (SAKATA, 2012).

Diante da influência do estado nutricional na evolução clínica de pacientes hospitalizados em UTI, surge a necessidade dos pacientes com TOT ou TQT usarem suporte nutricional, já que apresentavam déficit na função de deglutição. Dessa maneira, a quase totalidade dos pacientes utilizou algum tipo de via para alimentação que não a via oral.

Além do fato dos pacientes estarem impossibilitados de deglutir em função da prótese ventilatória, convém enfatizar que pacientes internados em UTI apresentam frequentemente imonunutrição, associada à resposta metabólica ao estresse, a qual promove intenso catabolismo e mobilização de proteínas para reparo de tecidos lesados e fornecimento de energia (DIESTEL et al., 2013).

Persp. online: biol. \& saúde, Campos dos Goytacazes, 25 (7), 1-24, 2017

seer.perspectivasonline.com.br 
O suporte nutricional oferecido ao paciente crítico através de sondas pode ocasionar possíveis complicações, que podem estar associadas a erros na sua introdução como estenose e perfuração do esôfago, pneumotórax, inserção da Sonda Nasogástrica (SNG) em brônquios possibilitando pneumonia aspirativa e eventualmente óbito, inúmeros fatores podem predispor à aspiração de conteúdo gástrico para o pulmão, principalmente nos pacientes críticos com rebaixamento do nível de consciência, posição supina, vômitos frequentes, idade avançada e principalmente em ventilação mecânica, este risco aumenta quando o tubo é posicionado próximo à transição esofagogástrica provocando refluxo gastroesofágico, ou quando ocorre deslocamento após tosse, náusea ou vômito (MALTA et al., 2013).

O tempo de permanência na UTI, variou de 2 à mais de 30 dias, onde 64,7\% encontravam-se internadas de 2 à 10 dias; 27,4\% pacientes 11 à 30 dias e 7,8\% pacientes permaneceram na UTI por mais de 30 dias, como ilustra a figura 1. Vale ressaltar que diante da revisão documental para obtenção dos dados, os pacientes desenvolveram pneumonia após o $4^{\circ} \mathrm{DIH}$.

\section{Tempo de Permanência na UTI}

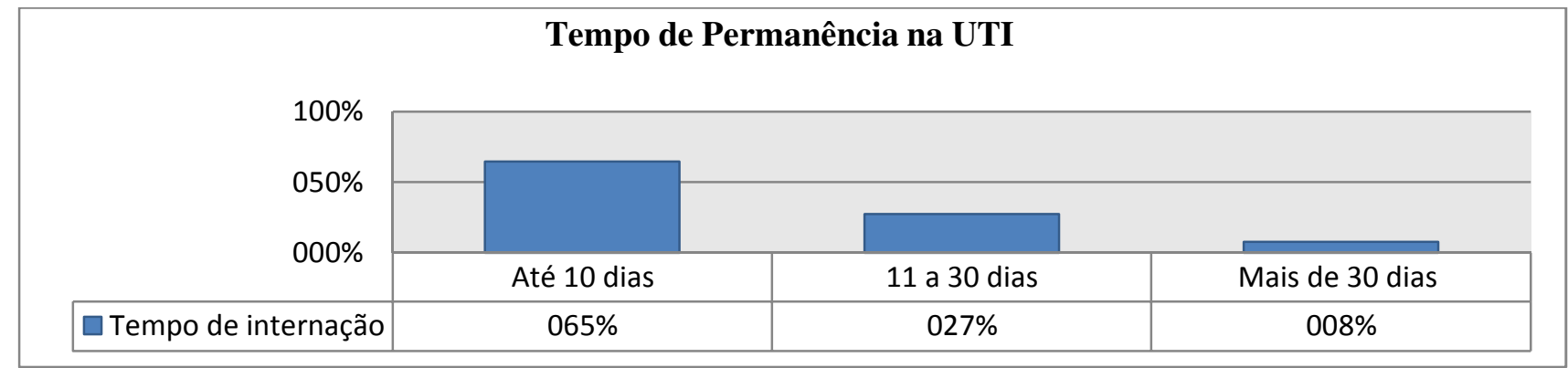

Figura 1: Distribuição dos pacientes segundo o tempo de permanência na Unidade de Terapia Intensiva - Campos dos Goytacazes, RJ - 2016.

Dado os inúmeros fatores de risco para desenvolvimento da pneumonia associada ao ventilador, o escore de gravidade do paciente na UTI, rebaixamento do nível de consciência e a permanência do mesmo no setor influenciam diretamente no prognóstico deste paciente, visto sua maior vulnerabilidade de adquirir infecções da própria microbiota do setor e pelos inúmeros procedimentos invasivos aos quais são submetidos.

Segundo Gomes; Santos (2016), a PAVM é a infecção pulmonar que desenvolve-se 48 a $72 \mathrm{~h}$ após intubação endotraqueal. Um estudo canadense mostrou que até o quinto dia de Ventilação Mecânica (VM) o risco de desenvolver pneumonia aumenta 3,3\% ao dia, ainda afirma que após este tempo o risco começa a diminuir, chegando a $1,3 \%$ no $15^{\circ}$ dia de $\mathrm{VM}$, isso reflete que o maior risco desenvolver PAVM ate o $5^{\circ}$ dia sendo causada principalmente por microorganismos comuns no trato respiratório e orofaringe.

Devido à incidência de PAVM nas UTIs, sua associação com o aumento do tempo de internação hospitalar e as possíveis complicações na UTI, é possível afirmar que os pacientes observados na pesquisa estão suscetíveis à pneumonia hospitalar pelo tempo de estadia no setor corroborando diretamente com a literatura.

\section{Clínica}

O diagnóstico prevalente especificado nos prontuários foi representado pelas pneumopatias, com 39,2\% pacientes, o diagnóstico de PAVM que constituiu 27,4\% pacientes descritos na Figura 2. Em seguida, por ordem de ocorrência, obteve-se: acidente vascular encefálico (AVE), com 17,6\% pacientes; sepse, com $5,8 \%$; e cardiopatias com $9,8 \%$ pacientes, mencionados na figura 2 .

Persp. online: biol. \& saúde, Campos dos Goytacazes, 25 (7), 1-24, 2017

seer.perspectivasonline.com.br 
Vale ressaltar que certas doenças foram agrupadas e inseridas no grupo das pneumopatias, incluindo as pneumonias e a doença pulmonar obstrutiva crônica (DPOC). Ambas são condições que afetam o trato respiratório do paciente podendo levar a complicações graves.

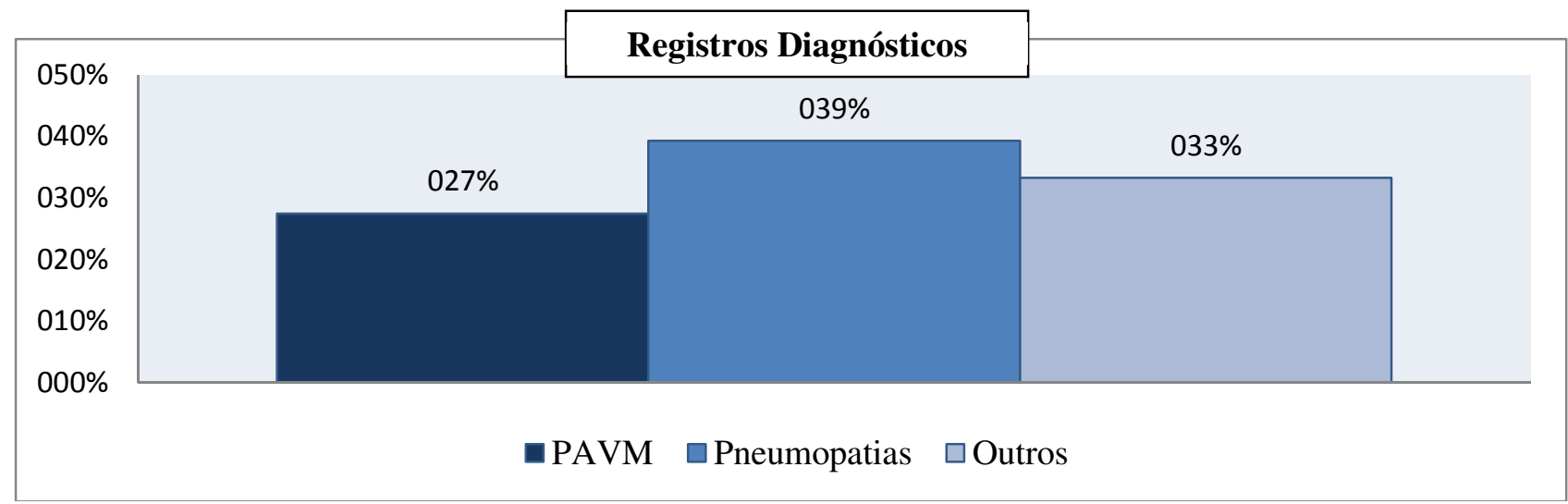

Figura 2: Distribuição dos pacientes segundo o diagnóstico médico internados na Unidade de Terapia Intensiva - Campos dos Goytacazes, RJ - 2016.

A pneumonia é considerada um das principais infecções na UTI, sendo responsável por elevada taxa mortalidade. Doenças crônicas, especialmente as cardiovasculares e pulmonares, nível de consciência reduzido, uso de nutrição enteral, diabetes, tabagismo e terapia imunossupressora, são fatores predisponentes para essa infecção (MELO et al., 2015).

Um estudo realizado em 2010 com pacientes internados em terapia intensiva obteve como principal diagnóstico responsável pelo desenvolvimento da PAVM a insuficiência respiratória aguda, representando $53,85 \%$ dos casos, assemelhando-se, de certo modo, aos achados desta pesquisa, visto que, as pneumopatias podem levar os pacientes a um quadro agudo mais grave, necessitando de maior permanência na UTI e consequentemente inúmeros procedimentos invasivos que podem favorecer o desenvolvimento da PAVM (PADRÃO et al., 2010).

Estudos epidemiológicos envolvendo pneumonias apresentam limitações relacionadas à dificuldade de realização do diagnóstico de certeza, ausência frequente de distinção entre pneumonia hospitalar e PAVM definidos nos trabalhos e dificuldades de análise de fatores de risco e de mortalidade (JÚNIOR, FERRAZ; LAPCHICK, 2015).

Reafirmando a dificuldade de diagnóstico de pneumonia e sua distinção, Araújo et al. (2015) defendem que atualmente não existe um teste padrão ouro e um método especifico para este diagnóstico em pacientes ventilados mecanicamente demostrando febre e síndrome de disfunção orgânica múltipla, representando um desafio para a detecção dessa doença.

Em contrapartida Silva et al. (2011) apontam que a suspeita clínica da presença de PAVM ocorre em função do aparecimento de um novo infiltrado pulmonar, ou à progressão de um infiltrado prévio na radiografia de tórax, associados a condições clínicas do paciente, alterações laboratoriais, como presença de febre, leucopenia, leucocitose e secreção purulenta.

Embora a definição diagnóstica de PAVM ainda seja um desafio, é necessário que todos os profissionais envolvidos com o paciente crítico reconheçam a importância dos fatores de risco modificáveis a cerca de prevenir o desenvolvimento da PAVM, especialmente à equipe de enfermagem que além de compor a força motriz nos serviços de saúde, é a classe que mais estabelece contato direto com os pacientes que em

Persp. online: biol. \& saúde, Campos dos Goytacazes, 25 (7), 1-24, 2017

seer.perspectivasonline.com.br 
sua grande maioria dependem exclusivamente dos cuidados da equipe para aumentar a sua sobrevida (ALMEIDA et al., 2015).

Sendo assim, a execução de medidas de prevenção baseadas em evidências científicas é capaz de reduzir a incidência PAVM de forma significativa e sustentada, trazendo segurança na assistência e redução de custos, livrando o paciente de todas as implicações clínicas de uma infecção do trato respiratório hospitalar (GUIMARÃES et al., 2011).

\section{Indicador de Avaliação de Adesão às Medidas de Prevenção e Controle de Pneumonia em Pacientes de Alto Risco (IRPR).}

O índice de conformidade geral em todas as medidas de prevenção e controle de PAVM, que considera a somatória das quatro medidas corretas ao mesmo tempo correspondeu a 33,3\%, como descrito o cálculo abaixo. Na tabela 2 são apresentados os dados referentes às observações realizadas no período da manhã no hospital referido de acordo com a conformidade e não conformidade geral.

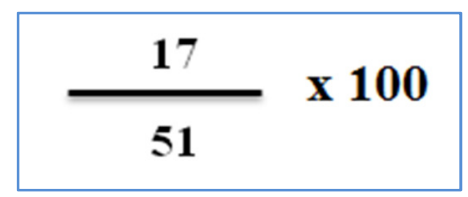

Tabela 2 - Distribuição das observações dos pacientes em números absolutos e os respectivos percentuais de conformidade geral e não conformidade geral das medidas específicas de prevenção e controle de pneumonia associada á ventilação mecânica da UTI - Campos dos Goytacazes, RJ - 2016.

\begin{tabular}{c|c|c}
\hline Item & N & $\%$ \\
\hline Número total & 51 & 100 \\
$N^{o}$ Total de Conformidade Geral & 17 & 33,3 \\
$N^{o}$ Total de Não conformidade Geral & 34 & 66,6 \\
\hline
\end{tabular}

As infecções Hospitalares (IHs) são consideradas um problema de saúde pública e ainda constituem risco significativo à saúde dos pacientes, e, dessa forma, sua prevenção e controle são de extrema importância e envolvem medidas de qualificação da assistência hospitalar, através de ações que resultem a melhoria da qualidade da assistência à saúde, reduzem esforços complicações e recursos.

Conforme o Manual de Indicadores de Avaliação da Qualidade de Práticas de Controle de Infecção Hospitalar, o uso de um sistema de avaliação e qualificação do controle e prevenção de infecções adquiridas em serviços de saúde necessita ser atualizados de forma constante, incorporando novas práticas e abordagens que respondam pela dinamicidade da evolução da assistência clínica e de novas evidências científicas (SÃO PAULO, 2006).

As avaliações através do IRPR exigiram o predomínio da observação direta na averiguação dos procedimentos, a manutenção da elevação cabeceira a $30-45^{\circ}$, uso de solução estéril nos umidificadores dos ventiladores mecânicos e implementação da rotina de troca de material de terapia inalatória, na qual pode-se observar os circuitos do ventilador mecânico que, segundo o protocolo da Comissão de Controle de Infecção Hospitalar $(\mathrm{CCIH})$ da instituição, devem ser trocados a cada 96 horas e se houver sujidade visível como

Persp. online: biol. \& saúde, Campos dos Goytacazes, 25 (7), 1-24, 2017

seer.perspectivasonline.com.br 
sangue e secreções. O atendimento da fisioterapia respiratória foi possível verificar através de seu registro no prontuário.

O processo de cuidar não é isento de riscos, que muitas vezes pode ocasionar danos de diferentes graus de gravidade, mesmo que a intenção tenha sido fornecer benefícios ao paciente. Diante dos inúmeros eventos adversos, salienta-se a complexidade dos cuidados de enfermagem associados a dispositivos invasivos, visto que, estes profissionais devem possuir competência técnica e habilidades para garantir a descontaminação, higiene, e manipulação adequada de todos os dispositivos que envolvem o cuidado a esses pacientes (LANZILLOTTI et al., 2013).

Rocha et al. (2012) contextualizam a importância do reconhecimento dos fatores que podem contribuir para o surgimento de complicações, bem como implementação de ações de prevenção, que em sua maioria compete ao enfermeiro a elaboração destes protocolos contendo algumas recomendações para reduzir a PAVM, que incluem medidas educativas para os profissionais de saúde, a vigilância epidemiológica das infecções hospitalares, a interrupção na transmissão de microrganismos pelo uso apropriado de equipamento hospitalar, a prevenção na transmissão de uma pessoa para outra e a modificação de fatores de risco para o desenvolvimento de infecções bacterianas

Diante disso Cogo et al. (2012), afirmam que o reconhecimento dos riscos e a implementação de medidas preventivas compõem algumas das etapas da Sistematização da Assistência de Enfermagem, considerada uma necessidade que deve se estender dos desenvolvimento profissional para o serviço de enfermagem por meio de sua operacionalização, que irá permear a organização, o planejamento de ações sistematizadas de gerenciamento e o cuidado do cliente que está no ambiente hospitalar. A mesma atende às necessidades do paciente em sua complexidade e constrói a autonomia profissional do enfermeiro mediante a sua equipe.

Paiano et al., (2014) expõem que a padronização das ações de enfermagem fundamentadas na SAE almeja qualificar o cuidado dispensado, oferecer atendimento planejado e individualizado, preservar a organização do setor, otimizar o tempo identificando as prioridades para a tomada de decisões, favorecer a valorização do profissional enfermeiro e consequentemente a valorização da equipe.

A tabela 3 permite verificar a conformidade e não conformidade de cada medida específica de prevenção e controle de PAVM. Verificou-se que cada medida, isolada obteve índice de conformidade sempre superior ao da conformidade geral $(33,3 \%)$, o qual associou todas as medidas por pacientes.

Tabela 3: Total de observações e índices de conformidade e não conformidade de cada medida específica de controle e prevenção de pneumonia associada à ventilação mecânica da Unidade de Terapia Intensiva - Campos dos Goytacazes, RJ - 2016.

\begin{tabular}{|c|c|c|c|c|c|}
\hline \multirow{2}{*}{ VARIÁVEIS } & \multirow{2}{*}{$\begin{array}{l}\text { Total } \\
100 \%\end{array}$} & \multicolumn{2}{|c|}{ Conformidade } & \multicolumn{2}{|c|}{ Não Conformidade } \\
\hline & & $\mathbf{n}$ & $\%$ & $\mathbf{n}$ & \\
\hline Uso de solução estéril & 51 & 23 & 45,0 & 28 & 55,0 \\
\hline Troca de material de Terapia Respiratória & 51 & 20 & 39,2 & 31 & 60,8 \\
\hline Atendimento da Fisioterapia & 51 & 27 & 52,9 & 24 & 47,1 \\
\hline Cabeceira elevada de $30-45^{\circ}$ & 51 & 29 & 56,8 & 22 & 43,2 \\
\hline
\end{tabular}

Calculando as medidas, isoladamente constatou-se que a "troca de circuito de terapia inalatória respeitando a rotina", foi a principal responsável pela não obtenção da conformidade geral, com $(60,8 \%)$.

Persp. online: biol. \& saúde, Campos dos Goytacazes, 25 (7), 1-24, 2017

seer.perspectivasonline.com.br 
Dentre todas as medidas, relacionado à conformidade nenhuma superou este índice, com o atendimento da fisioterapia alcançou $(52,9 \%)$ de conformidade e a cabeceira elevada $30-45^{\circ}(56,8 \%)$, constatando-se que tais recomendações estão bem estabelecidas na assistência ao paciente sob prótese ventilatória e além de constituírem medidas dos bundles de ventilação.

Vale ressaltar que durante a observação direta para verificar o uso de soluções estéreis para nebulizadores e umidificadores, foi obtido como resultado $55,0 \%$ de não conformidade, visto que, foram encontrados frascos de água destilada abertos ou seringas com soros fisiológicos preparados em balcões, conforme o manual do indicador clínico respalda como quesito na observação.

Com relação à manutenção da cabeceira elevada a 30-45 Almeida et al. (2015) afirmam que é uma medida simples e não demanda custos adicionais, considerada uma das principais recomendações para evitar broncoaspiração e, consequentemente a PAVM, que pode contribuir para uma melhoria no volume corrente e ventilatório, e minimizando os casos de atelectasia, embora esta seja uma prática simples, é necessário ser realizada com responsabilidade e valorizada pelos profissionais, visto que, configura um cuidado essencial na prevenção da pneumonia associada ao ventilador mecânico.

Contudo alguns estudos revelam que, a manutenção da cabeira elevada encontra algumas resistências na prática assistencial, com justificativas de que o paciente escorrega no leito. Como alternativa para cabeceira elevada, um estudo pioneiro mostrou que a posição de trendelenburg lateral como mostra a Figura 3, pode contribuir na prevenção de PAVM, visto que, este posicionamento além de evitar aspiração pulmonar contribui para limpeza do muco em pacientes intubados (LI BASSI; TORRES, 2011).

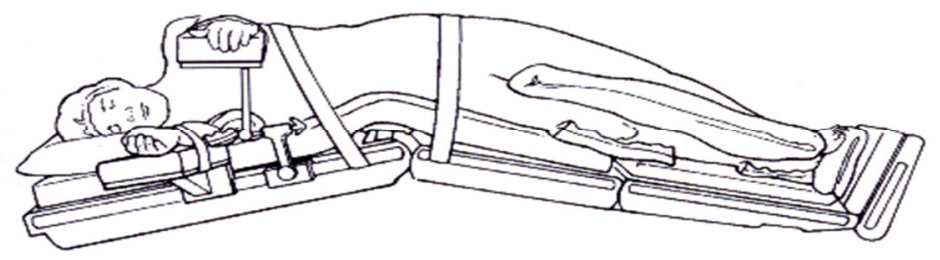

Figura 3: Posição Trendelenburg Lateral. Consiste no decúbito lateral, com o corpo inclinado para o lado, pernas e pés conforme o nível de cabeça. FONTE: Manual de procedimentos para estágio de enfermagem - São Paulo: Martinari, 2013.

Embora esta medida tenha sido realizada em conformidade com as propostas descritas em bundles implementados na UTI, alguns estudos demonstram que a aplicação desta medida ainda carece de maior incorporação pelos profissionais da saúde envolvidos na prática assistencial (SILVA et al., 2011).

Ainda sobre a tabela 3, com relação à troca do material de terapia inalatória respeitando o tempo de troca, obteve-se o percentual de $60,8 \%$ de não conformidade.

Assim, Cruz et al. (2011) afirmam que os acessórios da ventilação mecânica como o circuito do ventilador constituem uma fonte de patógenos, através da formação de condensado com acúmulo de líquido contaminado por patógenos do próprio paciente, pode ser fonte de infecção para o mesmo sendo necessária sua troca a segundo a rotina da instituição.

Em contrapartida Kusahara et al. (2012) apontam que quanto aos equipamentos de terapia inalatória não há vantagens significativas em trocar os circuitos do ventilador a cada 48 horas, uma vez que, os ventiladores mecânicos com umidificadores podem ter aumentado a condensação da tubulação, entretanto traz como medida de prevenção da PAVM a cautela em evitar o refluxo do líquido condensado na traqueia do paciente. 
Um estudo Europeu, realizado em 2010 abordou o pacote de cuidados Europeu de Prevenção de PAVM, e demonstrou que não há nenhuma necessidade de troca de circuito, exceto se especificamente indicada, mas propõem a importância da equipe de enfermagem em sua prática assistencial em evitar o desvio inadvertido de líquidos do circuito para o tubo, ou de volta para o umidificador durante manobras para modificar o decúbito do paciente, e ao se elevar a grade lateral do leito, quando se utiliza a nebulização (RELLO et al., 2010).

Diante desse contexto a equipe de enfermagem necessita possuir conhecimento referente às possíveis alterações hemodinâmicas, assim como as modalidades terapêuticas e aos cuidados específicos do manuseio adequado do ventilador mecânico, a fim de oferecer uma assistência qualificada, proporcionando mais chances de recuperação.

\section{Medidas de Controle e Prevenção de Pneumonia Associada à Ventilação Mecânica}

A higiene das mãos é considerada uma medida básica nos serviços de saúde como prática essencial na assistência. As mãos dos profissionais de saúde vêm sendo implicadas como fonte de transmissão de microrganismo no ambiente hospitalar, que são contaminadas por sua vez durante o contato direto com paciente ou indireto com produtos e equipamento no ambiente próximo a este, como bombas de infusão, barras protetoras dos leitos e estetoscópio, entre outros. Diante disso foi observado a higienização das mãos dos profissionais de enfermagem pré e pós realização de procedimentos dispensados aos pacientes críticos, descritos na Tabela 4.

Tabela 4: Higienização das mãos pré e pós procedimentos para prevenção da pneumonia associada ao ventilador mecânico, UTI - Campos dos Goytacazes, RJ 2016.

\begin{tabular}{l|c|c|c|c}
\hline \multicolumn{1}{c|}{ HIGIENIZAÇÃO DAS MÃOS } & \multicolumn{2}{c|}{ Pré-procedimento } & \multicolumn{2}{c}{ Pós - procedimento } \\
\hline & SIM & NÃO & SIM & NÃO \\
& $\mathrm{n}(\%)$ & $\mathrm{n}(\%)$ & $\mathrm{n}(\%)$ & $\mathrm{n}(\%)$ \\
1. Limpeza, desinfecção, montagem e teste do ventilador & $18(35,2)$ & $20(39,2)$ & $17(33,3)$ & $21(41,1)$ \\
2. Manuseio dos circuitos durante a VM & $20(39,2)$ & $31(60,7)$ & $35(68,6)$ & $16(31,3)$ \\
3. Troca e manuseio de frascos & $22(43,1)$ & $29(56,8)$ & $33(64,7)$ & $18(35,2)$ \\
4. Verificação de pressão cuff* & - & - & - & - \\
5. Posicionamento no leito & $40(78,4)$ & $11(21,5)$ & $45(88,2)$ & $6(11,7)$ \\
6. Higiene Brônquica & $31(60,7)$ & $20(39,2)$ & $35(68,6)$ & $16(31,3)$ \\
7. Higiene Bucal & $11(21,5)$ & $40(78,4)$ & $12(23,5)$ & $39(76,4)$ \\
\hline
\end{tabular}

*No período da pesquisa não foi possível observar a verificação da pressão do Cuff do tubo orotraqueal.

Perante o exposto, ressaltou-se neste estudo que a precaução universal, lavagem das mãos ou higienização das mãos pré e pós procedimentos dispensados a pacientes ventilados mecanicamente na 
tratamento intensivo, obteve pouca adesão especialmente no pós-procedimento, pela equipe de enfermagem que foram os profissionais que realizaram grande parte desse procedimentos.

Embora os cuidados relacionados aos circuitos, nebulizadores e filtro não façam parte dos bundles do ventilador, no entanto a falta de assepsia durante a montagem dos circuitos e manuseio inadequado dos nebulizadores e filtros são preocupantes nos resultado deste estudo.

É sabida a importância das precauções padrão, principalmente a lavagem das mãos, que foi apresentada como prática pouco aderida pela equipe de enfermagem, representando negativamente na assistência prestada, apesar das legalizações reforçarem o papel da lavagem das mãos como ação mais importante na prevenção e controle de infecções em serviços de saúde.

Corroborando com o estudo Silva et al. (2011) afirmam que há diversos registros na literatura que enfatizam a importância da transmissão da infecção cruzada como fonte de surtos de infecção relacionada à assistência à saúde principalmente na UTI. Ainda que indiretamente, e que não haja comprovação da colonização das mãos dos profissionais de saúde, já foi demonstrado que a baixa adesão à higienização das mãos era uma das causas dos surtos de colonização e infecção em centros intensivos agravando significativamente o quadro dos pacientes.

Nesse contexto Al-Tawfiq; Tambiah (2014), apontam que as infecções relacionadas à assistência à saúde (IRAS) são um problema de saúde pública, por representarem significativo risco à segurança do paciente e pelo impacto econômico que geram, especialmente, nos países em desenvolvimento, onde se observa que, quanto menor o desenvolvimento econômico, maiores os índices de IRAS.

A higienização das mãos é uma medida que deve ser incorporada por toda equipe multidisciplinar que compõe a UTI, sejam com a água e sabão líquido ou pelo uso do álcool a $70 \%$ antes e depois pré e pós todos os procedimentos realizados, visto que, a literatura mostra comprovação da alta eficácia na prevenção e controle de infecções (CAETANO et al., 2011).

Pereira et al. (2016) o enfermeiro quanto líder de toda equipe de enfermagem da UTI deve dispor de treinamentos e educação continuada diante das falhas, além de dispor de instrumentos que facilitem a entendimento e a realização de medidas de prevenção, visto que a assistência prestada é o aspecto fundamental para o processo de tratamento e reabilitação do paciente onde deve-se ser respaldado o conhecimento cientifico, para conduzir o atendimento do mesmo com a devida segurança.

Outra medida observada durante a pesquisa foi quanto à realização da higiene da cavidade oral, descritos na tabela 5, foi possível verificar que algumas etapas deste processo não foram executadas conforme o preconizado nos Bundles de ventilação, o que compromete significativamente a eficácia deste procedimento além de não assegurar a redução das taxas de PAVM. 
Tabela 5: Cuidados realizados na higienização bucal em pacientes críticos de uma Unidade de Terapia Intensiva - Campos dos Goytacazes, RJ - 2016.

\begin{tabular}{l|c|c}
\hline \multicolumn{2}{c}{ CIGIENIZAÇÃO BUCAL } & \% \\
\hline \multicolumn{1}{c}{ CUDADS } & N & 41,1 \\
1. Interrupção da dieta enteral antes do procedimento & 21 & 45,0 \\
2. Manteve cabeceira elevada durante o procedimento & 23 & --- \\
3. Verificou a pressão do cuff antes do procedimento * & --- & 7,8 \\
4. Aspirou vias aéreas durante o procedimento & 4 & 19,6 \\
5. Trocou fixação dos tubos & 10 & 100 \\
6. Realizou limpeza dos dentes & 51 & 68,6 \\
7. Higienizou a língua & 35 & 80,3 \\
8. Utilizou antisséptico ao termino do procedimento & 41 & 45,8 \\
9. Hidratou os lábios & 23 & 94,1 \\
10. Checou prescrição de enfermagem & 48 & 88,2 \\
11. Registrou procedimento no prontuário & 45 & \\
\hline
\end{tabular}

*No período da pesquisa não foi possível observar a verificação da pressão do Cuff do tubo orotraqueal.

Dentre as 51 possibilidades de observações com relação a higiene oral, a limpeza dos dentes foi feita com gazes envolvidas em espátula (abaixador de língua) em 68,6\% dos pacientes e 31,3\% em gazes envolvidas no próprio dedo.

Como exposto na tabela 5 a etapa que foi executada em todas as observações do estudo foi à limpeza dos dentes $100 \%$, seguida pela utilização de antissépticos ao término do procedimento $80,3 \%$.

O Bundle de ventilação traz enfoque na utilização de antissépticos como a clorexidina $(0,12 \%)$ para descontaminação da cavidade oral e concomitante redução da incidência infecção hospitalar especialmente a PAVM, ainda relata que o antisséptico deve ser utilizado a cada $12 \mathrm{~h}$, que permite a redução de mais de $30 \%$ da clorexidina nos tecidos moles, estendendo o período de atividade antimicrobiana e a limpeza simples da cavidade oral em no mínimo três vezes/dia utilizando solução oral (CRUZ, ARAÚJO; MOREIRA 2016).

Um estudo realizado nos Estados Unidos dividiu 547 pacientes internados na UTI em quatro grupos para os seguintes tratamentos, swab de clorexidina, solução oral três vezes ao dia, escovação três vezes ao dia e a realização tanto da escovação quanto o uso de clorexidina. Foi perceptível em três dias de análise que a clorexidina reduziu significativamente a incidência de PAVM a partir do terceiro dia (JONES et al., 2010).

Conforme Caldeira (2011), geralmente a técnica de higiene bucal não é seguida com o rigor necessário, isso se deve a falta de alguns procedimentos, assim como em relação a sua frequência, comprometendo sua qualidade, ainda como fator contribuinte, traz a utilização de substâncias que não oferecem as ações antissépticas desejadas para a redução da microbiota oral, gerando maior probabilidade de PAVM e complicações infecciosas que possam vir a comprometer a morbimortalidade dos pacientes internados na UTI. 
Vale destacar que outro aspecto observado durante a pesquisa foi que a equipe de enfermagem especialmente os técnicos foram os profissionais que realizaram a maioria dos procedimentos referentes à higiene oral dos pacientes.

Dado os riscos bacterianos oriundos da cavidade bucal que favorecem o desenvolvimento da PAVM, reforça-se a importância da completa limpeza cavidade, considerando a avaliação de um cirurgião dentista. Nos dias atuais não há padrão de higienização bucal em paciente na UTI quanto a quem deve executar o procedimento de forma privativa, a realidade é que os profissionais de enfermagem que realizam onde muitas vezes carecem de tempo hábil pela demanda de pacientes executar esta tarefa completamente (SANTOS et al., 2013).

A responsabilidade quanto à necessidade do cuidado bucal segue compartilhada e integrada entre a enfermagem e a odontologia, dada à importância e participação de um profissional cirurgião-dentista na equipe é condição fundamental para avaliar e acompanhar o acometimento da saúde bucal dos pacientes, em especial os pacientes em modalidade de ventilação mecânica (GOMES; ESTEVES, 2012).

Destacou-se ainda que no período de observação do estudo, não foi possível verificar a calibração da pressão do cuff do tubo orotraqueal, embora os estudos recomendem que a pressão deve ser aferida no mínimo três vezes por dia ou a cada quatro horas.

Embora não tenha sido possível observar a mensuração da pressão do cuff, salienta-se a responsabilidade da equipe de enfermagem e fisioterapia neste procedimento visto que, que é necessário manter insuflado numa pressão ideal para evitar escape de ar entre o tubo e a traqueia e o escoamento de bactérias os quais podem aumentar e dificultar a eliminação das secreções do trato respiratório (SANTOS; FIGUEIREDO, 2010).

Souza; Santana (2012) apontam que o tubo orotraqueal e a cânula de traqueostomia ambos apresentam o cuff, balonete indicado para vedar as vias aéreas inferiores durante a ventilação mecânica, o qual deve ser aferido a cada quatro horas e mantido insuflado com uma pressão ideal de 20 a $25 \mathrm{cmH} 2 \mathrm{O}$, visto que, a pressão superior pode levar a lesão da parede traqueal, a pressão inferior pode ocasionar broncoaspiração e consequentemente o desenvolvimento da PAVM.

Assim, a manutenção da correta pressão de cuff é essencial, uma vez que, a pressão excessiva ou insuficiente pode ocasionar complicações ao paciente em ventilação mecânica. Recomenda-se, portanto, que esta pressão permaneça entre 20 e $25 \mathrm{~cm} \mathrm{H}_{2} \mathrm{O}$, sendo verificado em pelo menos três vezes ao dia (BRASIL, 2013).

A manutenção dos níveis pressóricos propostos pela literatura tem sido um desafio na prática clínica, uma vez que, em UTIs são utilizados materiais como forma de improviso na mensuração da pressão, sendo considerado pela literatura ineficazes, além dos inúmeros fatores influenciam na variação desta pressão, como mudança no tônus da musculatura traqueal, hipotermia, e posição do paciente e do cuff, reforçando a necessidade de monitorização e de ajuste frequente da pressão de cuff com o manômetro especifico (ANNONI; JUNIOR 2015).

Embora os estudos relatem que inúmeras técnicas são incorporadas para mensuração da pressão de cuff, acredita-se que o método mais eficaz para atingir as pressões recomendadas seja aquele que se utiliza de um manômetro aneroide, geralmente portátil, específico para tal função. Entretanto, no Brasil, muitas unidades hospitalares não possuem tal dispositivo devido ao seu alto custo, e a pressão é verificada por aferições indiretas (GONÇALVES et al., 2012).

Diante disso, estudos demonstram que o monitoramento da pressão do balonete (cuff) além de compor uma medida essencial em pacientes críticos, são técnicas comprovadas e que estão descritas em

Persp. online: biol. \& saúde, Campos dos Goytacazes, 25 (7), 1-24, 2017

seer.perspectivasonline.com.br 
Bundles de ventilação, são capazes de reduzir significativamente o risco da aspiração de secreções respiratórias presentes no espaço supraglótico e consequentemente reduzindo as taxas de PAVM (PINTO et al., 2015).

Salienta-se a responsabilidade da equipe de enfermagem e de fisioterapeutas a verificação do cuff do tubo endotraqueal, manter a insuflação do volume com uma pressão ideal, para evitar escape de ar entre o tubo e a traqueia e o escoamento de bactérias, os quais podem aumentar e dificultar eliminação das secreções do trato respiratório inferior além de aumentar os riscos de PAVM (BORCK, GASPAR; RECHE 2015).

Outro cuidado recomendado para profilaxia de PAVM é a aspiração traqueal, visto que, o acúmulo de secreções nesse espaço está associado ao maior risco de desenvolvimento desse agravo (PEREIRA, 2016).

No que concerne à higiene brônquica, o sistema aberto de aspiração foi predominante realizado $72,5 \%$, e $27,4 \%$ foi utilizado sistema fechado de aspiração. Ficou evidente no estudo que a equipe de enfermagem foi o maior responsável pela execução desse procedimento em especial os enfermeiros, seguido pelos técnicos de enfermagem e fisioterapeutas.

Quanto os sistemas de aspiração aberto ou fechado são igualmente eficazes na remoção da secreção, entretanto o sistema fechado possui vantagem que em sua realização não é necessário à desconexão do respirador. Que conforme um estudo realizado na Grã-Bretanha em 2008 observou-se que não houve diferença entre os sistemas de aspiração aberto e fechado em relação à incidência de PAVM, tempo de internação na UTI ou mortalidade (SIEMPOS, VARDAKAS; FALAGAS 2008). 
Tabela 6: Cuidados com a higienização brônquica em pacientes críticos na UTI - Campos dos Goytacazes, RJ. 2016.

HIGIENIZAÇÃO BRÔNQUICA

\begin{tabular}{l|c|c}
\hline \multicolumn{1}{c|}{ CUIDADOS } & $\mathbf{N}$ & $\%$ \\
\hline 1. Interrompeu a dieta enteral durante o procedimento & 4 & 7,8 \\
\hline 2. Realizou pré-oxigenação (100\%) ou dobrou FiO' antes do procedimento & 6 & 11,7 \\
\hline 3. Abriu pacote do cateter aspiração e conectou cateter ao látex sem contaminar & 31 & 60,7 \\
\hline 4. Seguiu a sequência da aspiração & 36 & 70,5 \\
\hline 5. Trocou o cateter após a aspiração do tubo & 22 & 43,1 \\
\hline 6. Utilizou gaze estéril para limpar secreções no cateter & 48 & 94,1 \\
\hline 7. Teve contato com o cateter somente com luva estéril & 33 & 64,7 \\
\hline 8. Trocou luval cateter em caso de contaminação da luva ou cateter & 20 & 39,2 \\
\hline 9. Realizou hiperoxigenação após aspiração traqueal ou nos intervalos & 2 & 3,9 \\
\hline 10. Protegeu o látex após aspiração em embalagem limpa e seca & 50 & 98,0 \\
\hline 11. Reavaliou paciente após termino do procedimento & 7 & 13,7 \\
\hline 12. Anotou procedimento e características da secreção aspirada & 39 & 76,4 \\
\hline
\end{tabular}

Os profissionais da equipe multidisciplinar podem e devem realizar a aspiração traqueal desde que tenham treinamento específico e, dentre os envolvidos na prática diária estão os fisioterapeutas, enfermeiros, técnicos e auxiliares de enfermagem.

Com relação à equipe de enfermagem a Resolução COREN 012/2012 confirma este dado considerando o grau de formação cientifica e técnica dos profissionais de enfermagem, é estabelecido que compete a realização do procedimento de aspiração de pacientes internados em hospitais e congêneres ser de competência do Enfermeiro, técnico de enfermagem e do auxiliar de enfermagem, de acordo com suas qualificação técnicas o grau de complexidade desse atendimento mediante a prescrição de enfermagem.

Dessa maneira, a singularidade da assistência da equipe de enfermagem na UTI quanto às medidas de profilaxia da PAVM mais uma vez tem representado uma parcela significativa, por constituir a principal equipe frente às atividades assistenciais e gerenciais, dessa forma, a SAE, vem pra somar todo o processo assistencial garantindo ao profissional a qualificação do gerenciamento do cuidado e o planejamento de suas atividades, além de servir como guia para suas ações, uma vez que, estes pacientes necessitam de cuidado especializado a fim de minimizar os riscos de infecções hospitalares (CAMELO, 2012).

Assim a equipe de técnicos em enfermagem é a grande encarregada pela aplicação da prescrição de enfermagem, precisamente por colaborar com a avaliação do paciente no decorrer do cuidado dispensado, e é

Persp. online: biol. \& saúde, Campos dos Goytacazes, 25 (7), 1-24, 2017

seer.perspectivasonline.com.br 
de extrema importância que o enfermeiro oriente-os acerca da dimensão dos benefícios que a execução correta das prescrições pode oferecer, a fim de minimizar a resistência em praticá-las.

Brito, Silva; Montenegro (2012) afirmam que uma alternativa é a educação permanente no serviço da unidade de terapia intensiva contribui para a atualização, aperfeiçoamento e reciclagem dos conhecimentos, promovendo a adaptação do indivíduo frente pacientes gravemente enfermos que necessitam de cuidados ininterruptos.

Outro aspecto destacado na tabela 5 foi à técnica asséptica para conduzir o procedimento de higiene brônquica. Alguns critérios obtiveram um percentual positivo como abrir o pacote do cateter de aspiração e conectar o látex sem contaminar com $60,7 \%$, seguir a sequência da aspiração 70,5\%, utilização de gaze estéril para limpar secreções no cateter $94,1 \%$ e o contato com o cateter foi somente com luva estéril $64,7 \%$. Desse modo, ficou evidente que a técnica asséptica de aspiração do tubo orotraqueal foi seguida na maioria das vezes.

Reafirmando a importância da aspiração do tubo orotraqueal como medida de conforto e terapêutica do paciente, é essencial que sua realização seja em rigorosa da técnica asséptica por ser um procedimento invasivo que pode trazer agravos ao paciente. Dessa maneira, é imprescindível que o profissional possua não só domínio técnico, como também o conhecimento da fisiopatologia do problema respiratório do paciente, pois, somente assim, o procedimento poderá ser aplicado de maneira segura, interferindo o mínimo possível na evolução e no sucesso do tratamento (COCENTINO, 2012).

Com relação à realização da pré-oxigenação e hiperoxigenação nos intervalos ou no término do procedimento ficou evidente que essas medidas não foram levadas em consideração na maioria das vezes, a pré-oxigenação com $11,7 \%$ e a hiperoxigenação obteve $3,9 \%$, entretanto estes procedimentos remetem contradições entre autores Ambrozin et al. (2013), ressaltam que deve-se hiperoxigenar o paciente minutos antes da aspiração, para prevenir hipoxemia e consequentemente não agravar o seu quadro clínico. Corrêa et al. (2014), salientam durante pesquisa que nos Estados Unidos muitas instituições realizam esta conduta. Já, Marras \& Lanpena (2015) afirmam que uma concentração muito elevada de oxigênio pode levar a efeitos tóxicos, como alterações da fisiologia normal, podendo ocorrer depressão da respiração, diminuição do débito cardíaco, vasoconstrição sistêmica, vasodilatação pulmonar, e traqueobronquite.

Outra medida importante obteve baixa adesão quanto prevenção de PAVM, foi cessar a dieta para aspiração com 7,8\% que segundo Diestel et al. (2013), afirmam que métodos são utilizados para prevenir a aspiração pulmonar que envolve o controle do conteúdo gástrico, redução do refluxo gastroesofágico e proteção das vias aéreas, destacando que a interrupção da dieta antes de aspirar o paciente compõe uma medida importante. Malta et al. (2013) reforçam que os pacientes com risco de aspiração sob uso de sondas digestivas, além da necessidade de cessar a dieta antes do procedimento, devem ser posicionados horizontalmente com dorso elevado em relação ao restante do corpo, onde esta posição evitará a regurgitação, mas caso aconteça, deve-se mudar imediatamente a posição da mesa de maneira que a cabeça fique posicionada abaixo do tronco, evitando-se aspiração e consequentemente a PAVM.

\section{CONCLUSÕES}

A PAVM constitui o evento adverso mais frequente na UTI, no entanto, analisar sua incidência não é tarefa fácil, devido às muitas variáveis que podem estar associadas ao seu desenvolvimento, a baixa qualidade dos registros, a dificuldade em se obter dados confiáveis, ou ainda, a falta de padronização das ações de vigilância, mesmo quando se dispõe de recursos sofisticados.

No que tange os resultados obtidos no estudo, evidenciou-se na UTI do hospital referido um percentual significativo de pacientes diagnosticados com PAVM referente a 27,4\%. Pode-se ressaltar ainda a

Persp. online: biol. \& saúde, Campos dos Goytacazes, 25 (7), 1-24, 2017

seer.perspectivasonline.com.br 
conformidade de geral das medidas de controle e prevenção com $33,3 \%$ e a não conformidade geral foi $66,6 \%$.

Este cenário demonstrou que as medidas foram realizadas de forma insatisfatória, ficando evidente que apesar de serem recomendações simples e que demandam pouco tempo para serem realizadas houve baixa adesão dos profissionais a essas medidas essenciais para minimizar a incidência de PAVM.

Por conseguinte o cuidado interdisciplinar pode oferecer inúmeras vantagens ao paciente crítico fundamentado em evidencias científicas, como a implementação de Bundles, que veem pra substituir as medidas isoladas de prevenção. Além de confirmar a importância de ações educativas permanentes e de fortalecer a importância da SAE na UTI frente às prescrições de enfermagem voltadas a profilaxia da pneumonia.

Dessa forma o estudo apontou métodos contidos em bundles que devem ser incorporados na prática assistencial, objetivando reduzir consideravelmente a incidência de PAVM. O conjunto de ações, atribuídas à enfermagem são o alicerce para prevenção desta pneumonia visto que esses profissionais são responsáveis por mediar processo de trabalho que irá promover a assistência e direcionar o cuidado, proporcionando não somente a segurança do paciente, como também a dos profissionais envolvidos.

Diante da gama de eventos adversos, salienta-se a complexidade dos cuidados de enfermagem associados a dispositivos invasivos. Dessa maneira é fundamental que ações de prevenção de PAVM sejam implantadas de forma prioritária em todas as instituições de saúde, com intuito de minimizar esta incidência e promover maior segurança dos pacientes que necessitam de assistência ventilatória invasiva durante sua internação na UTI, contudo estratégias para redução dessas infecções são complexas, pois existem muitos fatores a serem considerados como os cuidados da equipe multiprofissional, o ambiente hospitalar, a condição clínica do paciente, o tipo do patógeno, e o uso de antimicrobianos.

Com isso, o enfermeiro necessita desenvolver seu trabalho fundamentado na SAE, com foco principal na identificação das necessidades do paciente, apontando um plano direcionado ao seu atendimento e cuidado, conduzindo a equipe de enfermagem nas ações a serem realizadas, com um processo dinâmico onde carece de conhecimento técnico-científico na prática assistencial reconhecendo a importância dos fatores que podem contribuir para o surgimento dessas infecções, bem como implementar ações para prevenir essas complicações.

Conclui-se que o estudo possibilitou ampliar os conhecimentos sobre os mecanismos da VM, correlacionados com benefícios e consequências oriundos deste complexo. Foi possível ainda elucidar uma reflexão a cerca da importância sensibilização da equipe de interdisciplinar para proporcionar um cuidado seguro ao paciente, contribuindo de forma significativa para um bom prognóstico do paciente minimizando os riscos e aumentando a sobrevida.

\section{AGRADECIMENTOS}

As instituições de pesquisa Hospital Ferreira Machado (HFM) e ao Hospital Geral de Guarus (HGG), por abrirem suas portas e disponibilizarem o campo para que nossa pesquisa fosse realizada com sucesso, agradecemos também pela recepção de cada encontro, pela gentileza de cada funcionário em especial a Edmery e a Gilberto. 


\section{REFERÊNCIAS}

ALMEIDA, K.M.V.; BARROS, O.M.C.; SANTOS, G.J.C.; VALENÇA, M.P.; CAVALCANTI, A.T.A.; FERREIRA, K.O. Adesão às medidas de prevenção para pneumonia associada à ventilação mecânica. Rev Enferm UFSM. Recife, PE. v.5, n.2, p.247, Abr/jun. 2015.

AL-TAWFIQ, J.A.; TAMBIAH, P.A. Healthcare associated infections (HAI) perspectives. J Infect Public Health. v.7, n.4, p.339. Jul/Ago. 2014.

AMBROZIN, A.R.P.; GONÇALVES, A.C.C.; ROSA, C.M.; NAVEGA, M.T. Efeitos da higienização brônquica nas variáveis cardiorrespiratórias de pacientes em ventilação mecânica. Fisioter Mov. v.26, n.2, p.251. Abr/Jun. 2013.

ANNONI, R.; JUNIOR, A.E.A. Manômetros artesanais não medem com precisão a pressão de balão dos tubos endotraqueais. Rev Bras Ter Intensiva. Minas Gerais. v.27, n.3, p.228. Fev/Ago. 2015.

ARAÚJO, M.C.; GEISEL, P.P.; LAGES, A.C.R.; ELMILRO, N.S.; PEREIRA, D.A.G. Fatores associados ao tempo de ventilação mecânica em pacientes submetidos a cirurgia cardíaca. ASSOBRAFIR Ciência. n.6, v.3, p.21. dez . 2015.

BORK, L.C.A.; GASPAR, M.D.R.; RECHE, P.M. Adesão às medidas preventivas de pneumonia associada à ventilação mecânica. Revista Epidemiologia e Controle de Infecção. v. 5, n. 1, p.12. Jan/Mar. 2015.

BRASIL. Agência Nacional de Vigilância Sanitária - ANVISA. Medidas de Prevenção de Infecção Relacionada à Assistência à Saúde. Brasília: ANVISA, 2013. 87p. Disponível em: http://www20.anvisa.gov.br/segurancadopaciente/images/documentos/livros/Livro4-

MedidasPrevencaoIRASaude.pdf. Acessado: 12 maio. 2015.

BRASIL. Ministério da Saúde. DATASUS. Pneumonia é a maior responsável pelas hospitalizações de acordo com relatório do sistema do DATASUS. Março. 2014. Disponível em: http://datasus.saude.gov.br/nucleos-regionais/sao-paulo/noticias-sao-paulo/402-pneumonia-e-a-maiorresponsavel-pelas-hospitalizacoes-de-acordo-com-relatorio-do-sistema-do-datasus. Acessado: 25 fev. 2015.

BRITO, C.G. N. S.; SILVA, N. C.; MONTENEGRO, L. Metodologia de Paulo Freire no desenvolvimento da educação permanente do enfermeiro intensivista. Enfermagem Revista. v. 16, n.3, p7. 2012.

CAETANO, J.A.; LIMA, M.A.; MIRANDA, M.C.; SERUFO, J.C.; PONTE, P.R.L. Identificação de contaminação bacteriana no sabão líquido de uso hospitalar. Rev Esc Enferm USP. vol.45, n.1, p.153. São Paulo. 2011.

CALDEIRA, P.M. Higiene oral de pacientes em entubação orotraqueal em uma Unidade de Terapia Intensiva. Revista Enfermagem Integrada. v.4, n.1, p.731. 2011.

CALIL, K.; VALENTE, G.; SORAIA. C.; SILVINO, Z. R. Ações e/ou intervenções de enfermagem para prevenção de infecções hospitalares em pacientes gravemente enfermos: uma revisão integrativa. Enfermería Global, Murcia (Espanha). v. 13, n. 34, p. 406. Abr. 2014.

CAMELO, Silvia Helena Henriques. Competência profissional do enfermeiro para atuar em Unidades de Terapia Intensiva: uma revisão integrativa. Revista Latino Americana de Enfermagem. Ribeirão Preto. v.20, n.1, p.192. Jan/Fev. 2012.

CARDOSO, L. SIMONETI, F.S.; CAMACHO, E.C.; LUCENA, R.V.; GUERRA, A.C.; RODRIGUES, J.M.S. Intubação orotraqueal prolongada e a indicação de traqueostomia. Revista Faculdade Ciência Médica Sorocaba. São Paulo. v.16, n.4, p.354. 2014.

CENTER FOR DISEASE CONTROL AND PREVENTION - CDC. Guidelines for preventing health-careassociated pneumonia: recommendations of CDC and the Healthcare Infection Control Practices Advisory Committee. MMWR, Atlanta, v. 53. 2016. 
CHAGAS, D.C.; PEREIRA, D.A.; CASTRO, F.L.M. Qualidade da assistência de enfermagem no setor de urgência de um hospital público de Teresina. R. Interdisciplinar. Teresina. v.8, n.1, p.332. Jan/Mar. 2015.

COCENTINO, B.C.B. Impacto da implantação do bundle de pneumonia associada à ventilação mecânica em diferentes perfis de pacientes de terapia intensiva. Journal of Infection Control, v. 1, n. 3. p.34. 2012.

COFEN. Resolução 358/2009. Dispõe sobre a Sistematização da Assistência de Enfermagem e a implementação do Processo de Enfermagem em ambientes, públicos ou privados, em que ocorre o cuidado profissional de Enfermagem, e dá outras providências. Rio de Janeiro, 2009.

COREN. Resolução 012/2012. Dispõe sobre a aspiração de pacientes internados em hospitais, de quem é a competência. Considerando nos auto do Processo nº 089/2012; Art. $2^{\circ} .2012$.

COGO, E. et al. Sistematização da assistência de enfermagem no cenário hospitalar: percepção dos enfermeiros. Cogitare Enfermagem. Jul/Set. v.17, n.3, p.513. 2012.

COLAÇO, A. et al. Registro da avaliação de enfermagem em terapia intensiva: Discurso do Sujeito Coletivo. Revista de Enfermagem da UFSM. v.5, n.2. p.257. 2015.

CORRÊA, R.A.; LUNA, C.M.; DOS ANJOS, J.C.F.V.; BARBOSA, E.A.; REZENDE, C.J.; REZENDE, A.P.; PEREIRA, F.H.; ROCHA, M.O.C. Cultura quantitativa de aspirado traqueal e lavado broncoalveolar no manejo de pacientes com pneumonia associada à ventilação mecânica: um ensaio clínico randomizado.. J Bras Pneumol. Minas Gerais. v.40, n.6, p.643Dez/Mai. 2014.

CRUZ, F. L. C.; MENESES, M.R.R.; SERRA, S.C.; BARBOSA, M.C.G. Pneumonia associada a ventilação mecânica: medidas preventivas. Revista de Pesquisa em Saúde. São Luís do Maranhão. v. 12, n. 1, p.56. Jan./Abr. 2011.

CRUZ, R.A.O.; ARAÚJO, A.A.; MOREIRA, T.P. Enfermagem e odontologia: perspectivas para a integração no cuidado ao paciente crítico. Revista Brasileira de Educação e Saúde. Pombal - PB. v.6, n.1, p.10. Jan/Mar 2016.

DIESTEL, C.F.; RODRIGUES, M.G.; PINTO, F.M.; ROCHA, M.R.; SÁ, P.S. Terapia nutricional no paciente crítico.. Revista HUPE. Rio de Janeiro. v.12, n.3, p.78, 2013.

DIRETRIZES DA SOCIEDADE BRASILEIRA DE PNEUMOLOGIA E TISIOLOGIA PARA O MANEJO DA ASMA. Jornal Brasileiro de Pneumologia. v.38, n.1, p.S1-S46. Abril. 2013.

FERREIRA, L.L.; CAVENAGHI, O,M.; Traqueostomia precoce no desmame da ventilação mecânica. Revista Brasileira Clinica Medica. São José do Rio Preto, SP. v.9, n.6, p.432-6, 2011.

GOMES, R.H.S.; SANTOS, R.S. Avaliação da capacidade e comprometimento funcional em pacientes traqueotomizados de um hospital público de Curitiba. Rev. CEFAC. Curitiba-PR. v.18, n.1, p.120-128. Jan/Fev. 2016.

GOMES, S.F.; ESTEVES, M.C.L. Atuação do cirurgiãodentista na UTI: um novo paradigma. Rev. Bras. Odontol. Vol. 69, n. 1, p.67-70, 2012.

GONÇALVES, F.A.F.; BRASIL, V.V.; RIBEIRO, L.C.M. TIPPLE, A.F.V. Ações de enfermagem na profilaxia da pneumonia associada à ventilação mecânica. Acta Paul Enferm. Goiânia/GO. v.25, n.1, p.1017 Mar/Ago. 2012.

GUIMARÃES, A.C.; DONALISIO, M.R.; SANTIAGO, T.H.R.; FREIRE, J.B. Óbitos associados à infecção hospitalar, ocorridos em um hospital geral de Sumaré-SP, Brasil. Revista Brasileira Enfermagem. v.64, n.5, p.864-9. Set/Out. 2011.

Institute for Healthcare Improvement. 5 Milion Lives Campaign. Getting Started kit: Prevent Ventilador Associated Pneumonia. Cambridge, Massachussttes; 2008.

JERÔNIMO, S.A.R. - Técnicas de UTI - Editora Riddel, São Paulo, 2010. p.9. 
JONES, D.J.; MUNRO, C.L.; GRAP, M.J.; KITTEN, T.; EDMOND, M. Oral care and bacteremia risk in mechanically ventilated adults. Heart Lung. v.39, n.6, p. 57-65. Nov/Dec. 2010.

JÚNIOR, S.A.P.; FERRAZ, R.R.N.; LAPCHICK, M.S. Pneumonia associada à ventilação mecânica como indicador de qualidade e segurança em saúde. Rev Med Minas Gerais. v.25, n.4, p.517-522. Jan/Jul. 2015.

KUSAHARA, D. M.; CANEZIN, C.C.S.; PETERLINI, M.A.S.; PEDREIRA, M.L.G. Colonização e translocação bacteriana orofaríngea, gástrica e traqueal em crianças submetidas à ventilação pulmonar mecânica. Acta Paulista de Enfermagem. São Paulo. v. 25, n. 03, p.393-400. Set 2012.

LANZILLOTTI, L.S.; SETA, M.H.; ANDRADE, C.L.T.; JUNIOR, W.V.M. Eventos adversos e outros incidentes na unidade de terapia intensiva neonatal. Rio de Janeiro. v.20, n.3, p.937-946. 2013.

LI BASSI, G.; TORRES, A. Ventilator-associated pneumonia: role of positioning. Curr Opin Crit Care. v.17, n.1, p.57-63. feb. 2011.

LISBOA, D.D.J.; MEDEIROS, E.F.; ALEGRETI, L.G.; BADALOTTO, D.; MARASCHIN, R. Perfil de pacientes em ventilação mecânica invasiva em uma unidade de terapia intensiva. J biotec biodivers. Vol.3, n.1, p.18-24, Dez. 2012.

MALTA, M.A.; CARVALHO, A.F.; ANDREOLLO, N.A.; FREITAS, M.I.P. Medidas antropométricas na introdução da sonda nasogástrica para nutrição enteral empregando a esofagogastroduodenoscopia. Arquivo Brasileiro Cir Dig. Campinas, SP. v.26, n.2, p.107-111. 2013.

MARRAS, M.A.; LAPENA, S.A.B. Atuação da equipe multidisciplinar no combate à infecções hospitalares. J Health Sci Inst. São José dos Campos-SP. v.33, n.1, p.37-44. 2015.

MARTINEZ, B.P.; MARQUES, T.I.; SANTOS, D.R.; SILVA, V.S.; JÚNIOR, B.R.N.; ALVES, G.A.A.; NETO, M.G.; JUNIOR, L.A.F. Influência de diferentes graus de elevação da cabeceira na mecânica respiratória de pacientes ventilados mecanicamente. Revista Brasileira de Terapia Intensiva. Salvador - BA. vol.27, n.4, p.347-35 Jul/Set. 2015.

MASSAROLI, R.; MARTINI, J.G.; MASSAROLI, A.; LAZZARI, D.D.; OLIVEIRA, S.N.; MELO, E.M.; BARBOSA, A.A.; SILVA, J.L.A.; SOMBRA, R.L.S.; STUDART, R.M.B.; LIMA, F.E.T.; VERSA, J.E.G.L.F. Evolução clínica dos pacientes em uso de ventilação mecânica em unidade de terapia intensiva. Rev enferm UFPE. Recife. v.9, n.2, p.610-16. Fev. 2015.

MELO, E.M.; BARBOSA, A.A.; SILVA, J.L.A.; SOMBRA, R.L.S.; STUDART, R.M.B.; LIMA, F.E.T.; VERSA, J.E.G.L.F. Evolução clínica dos pacientes em uso de ventilação mecânica em unidade de terapia intensiva. Rev enferm UFPE. Recife. v.9, n.2, p.610-16, Fev. 2015.

PADRÃO, M.C.; MONTEIRO, M.L.; MACIEL, N.R.; VIANA, F.F.C.F.; FREITAS, N.A. Prevalência de infecções hospitalares em unidade de terapia intensiva. Rev bras clin med. v.8, n.2, p.125-128. 2010.

PAIANO, L. A. G. et al. Padronização das ações de enfermagem prescritas para pacientes clínicos e cirúrgicos em um hospital universitário. Revista de Enfermagem do Centro-Oeste Mineiro. v.3, n.4, p.13361348. 2015.

PEREIRA, F.G.F.; CHAGAS, A.N.S.; FREITAS, M.M.C.; BARROS, L.M.; CAETANO, J.A. Caracterização das infecções relacionadas à assistência à saúde em uma Unidade de Terapia Intensiva. Revista Vida em debate sociedade, ciência e tecnologia. Fortaleza, CE. v.21, n.1, p.90-94. 2016.

PERUGINI, M.R.E.; PERUGINI, V.H.; FIGUEIRA, F.D.; FONTANA, L.M.S.; DINIZ, J.J.; SANTOS, D.L.; BELEI, R.A.; VESPERO, E.C.; PELISSON, M.; STIPP-ABE, A.T.; CAPOBIANGO, J.D. Impacto de um bundle nas taxas de pneumonia associada à ventilação mecânica (PAV) em uma unidade de terapia intensiva pediátrica em Londrina-PR. Semina: Ciências Biológicas e da Saúde, Londrina. v.35, n.2, p.259. Ago. 2015.

Persp. online: biol. \& saúde, Campos dos Goytacazes, 25 (7), 1-24, 2017

seer.perspectivasonline.com.br 
PINTO, D.M.; SCHONS, E.S.; BUSANELLO, J.; COSTA, V.Z. Segurança do paciente e a prevenção de lesões cutâneo-mucosas associadas aos dispositivos invasivos nas vias aéreas. Rev Esc Enfermagem da USP. São Paulo. v.49, n.5, p.775-782. Set/Jul. 2015.

RELLO, J.; LODE, H.; CORNAGLIA, G.; MASTERTON, R. A European care bundle for prevention of ventilator-associated pneumonia. Intensive Care Med. Europe. v.36, n.5, p. 773-780, Mar. 2010.

ROCHA, A. M.; MATTIA, A.L.; NASCIMENTO, D.C.; VIANNA, M.S.; CARVALHO, R.L.R. Análise das necessidades de assistência de enfermagem de pacientes internados em um centro de terapia intensiva para adultos. REME - Revista mineira de Enfermagem. Minas Gerais. v.16, n.3, p. 429-436, Dez/Jul. 2012.

SAKATA, R. K. Analgesia e Sedação em Unidade de Terapia Intensiva. Revista Brasileira Anestesiologia. v.60, n.6, p.648-658, Nov/Dez. 2012.

SALVADOR, P.T.C.O.; SANTOS, V.G.; BARROS, A.G.; ALVES, K.Y.A.; LIMA, K.Y.N. Ensino da sistematização da assistência de enfermagem aos técnicos de enfermagem. Esc Anna Nery. Rio Grande do Norte. Natal - RN. vol.19, n.4, pp.557-562, Out/dez. 2015.

SANTOS, P.S.S.; MARIANO, M.; KALLAS, M.S.; VILELA, M.C.N. Impacto da remoção de biofilme lingual em pacientes sob ventilação mecânica. Rev Bras Ter Intensiva. v.25, n.1, p.44-48. 2013.

SANTOS, V.F.D.R.; FIGUEIREDO, A.E.P.L. Intervenção e atividades propostas para o diagnóstico de enfermagem-ventilação espontânea prejudicada. Acta Paul Enferm. v.23, n.6, p.824-30.2010.

SECRETARIA DA SAÚDE DO ESTADO DE SÃO PAULO. Divisão de Infecção Hospitalar, Centro de Vigilância Epidemiológica. Manual de avaliação da qualidade de praticas de controle de infecção hospitalar. São Paulo (SP): Secretaria da Saúde do estado de São Paulo; 2006.

SIEMPOS, I.I.; VARDAKAS, K.Z.; FALAGAS, M.E. Closed tracheal suction systems for prevention of ventilator associated pneumonia. Br J Anaesth. v.100, n.3, p.299-306. 2008.

SILVA, L.T.R.; LAUS, A.M.; CANINI, S.R.M.S.; HAYASHIDA, M. Avaliação das medidas de prevenção e controle de pneumonia associada à ventilação mecânica. Revista Latino-Americana Enfermagem. Ribeirão Preto, SP. v.19, n.6, p.9, Nov/Dez. 2011.

SILVA, R.M.; SILVESTRE, M.O.; ZOCCHE, T.L.; SAKAE. Pneumonia associada à ventilação mecânica: fatores de risco. Revista Brasileira Clinica Medica. São Paulo. v.9, n.1, p.5-10. Jan/Fev. 2011.

SILVA, S.G.; NASCIMENTO, E.R.P.; SALLES, R.K. Bundle de prevenção da pneumonia associada à ventilação mecânica: uma construção coletiva. Texto Contexto Enfermagem. Florianópolis. v.21, n.4, p.83744.Out/Dez. 2012.

SILVA, Sandra Regina.; SILVA, M.T. Manual de procedimento para estágio em enfermagem. $4^{\circ}$ ed. _ São Paulo: Marinari, 2013.

SOUZA, C.R.; SANTANA, V.T.S. Impacto da aspiração supra-cuff na prevenção da pneumonia associada a ventilação mecânica. Revista Brasileira de Terapia Intensiva. São Bernardo do Campo. SP. v.24, n.4, p.401406, 2012. 